\title{
Cholera, Migration, and Global Health - A Critical Review
}

\author{
Niyi Awofeso ${ }^{1 *}$, Kefah Aldabk ${ }^{1}$ \\ ${ }^{1}$ Hamdan Bin Mohammed Smart University, Dubai, UAE \\ Corresponding Author: Niyi Awofeso, PhD, Professor, Hamdan Bin Mohammed Smart University, Dubai, UAE.
} Tel: +97-144241018, Email: a.awofeso@hbmsu.ac.ae

Received February 1, 2018; Accepted April 7, 2018; Online Published September 25, 2018

\begin{abstract}
Cholera is an acute diarrheal infection caused by the ingestion of food or water contaminated with the bacterium Vibrio cholerae. The causative agent of this disease was originally described by Filippo Pacini in 1854, and afterwards further analyzed by Robert Koch in 1884 . It is estimated that each year there are 1.3 million to 4 million cases of cholera, and 21000 to 143000 deaths worldwide from the disease. Cholera remains a global threat to public health and an indicator of inequity and lack of social development. A global strategy on cholera control with a target to reduce cholera deaths by $90 \%$ was launched in 2017 . Before 1817, cholera was confined to India's Bay of Bengal. However, primarily following trade and migration between India and Europe, by the 1830s, cholera had spread internationally. The global spread of cholera was the driving force behind the first International Sanitary Conference in Paris, in 1851. The global health significance of cholera is underscored by its inclusion as one of four priority diseases in the 1969 and 2005 International Health Regulations. This article reviews the evolution of seven cholera pandemics and their reciprocal impacts on migration and global health. Also discussed are global efforts to address cholera, particularly the International Health Regulations, the 1969 and 2005 version of which stipulated that cholera epidemics require mandatory reporting to the IHR. This article concludes with a brief case study of Yemen's unprecedented cholera epidemic.
\end{abstract}

Keywords: Cholera, Quarantine, Global Health, Pandemics, International Health Regulations

Citation: Awofeso N, Aldabk K. Cholera, migration, and global health - a critical review. Int J Travel Med Glob Health. 2018;6(3):92-99. doi:10.15171/ijtmgh.2018.19.

\section{Introduction}

Cholera is an acute diarrheal infection caused by the ingestion of food or water contaminated with the bacterium Vibrio cholerae. Vibrio cholerae is a member of the family Vibrionaceae, which includes 3 medically important genera of water-dwelling bacteria. It is a short, gram-negative, rodshaped bacterium that appears curved when isolated. There are more than 200 different serogroups of V. cholerae, which are distinguished based on the structure of a protein called the $\mathrm{O}$ antigen in the bacterium's cell wall. Several of these serogroups are pathogenic in humans; however, only 2 serogroups of $V$. cholerae-O1 and $\mathrm{O} 139$ (sometimes called the Bengal serogroup)-are known to cause cholera. Pathogenic O1 and O139 V. cholerae have the ability to produce cholera toxin, a type of enterotoxin that affects intestinal cells. Pathogenic organisms in the $\mathrm{O} 1$ serogroup have caused the majority of cholera outbreaks and are subdivided into 2 biotypes: classical and El Tor. These 2 biotypes each contain 2 serotypes, called Inaba and Ogawa, which are differentiated based on their biochemical properties. ${ }^{1}$
The term "cholera" comes from the Greek words chole meaning bile and cholèdra, meaning gutter. Both words describe the expulsion of fluids from the body through diarrhea. In Iran, the Persian words "margamargi" (death and dying) and "maraz-e mout" (the illness of dying) were commonly used to describe cholera. The maritime trade with ports of India and pilgrimage to Mecca and Iraq's holy cities played significant roles in the dissemination of the illness among Iranian pilgrims during epidemics. In 19th century traditional Iranian medicine, cholera was associated with bad weather. One of the earliest Iranian books on cholera was written by Mirza Tehrani in 1858, entitled "Wabbayeh" (Cholera) ${ }^{2,3} V$. cholerae, the causative agent of this disease, was originally described by Filippo Pacini in 1854 . Following the death of a cholera patient during an epidemic in Florence, he performed an autopsy in which he conducted a histological examination of the intestinal mucosa. Pacini first discovered a comma-shaped bacillus which he described as "vibrio". He published a paper in 1854 entitled "Microscopical observations and pathological deduction on cholera," in which he described

Copyright $\odot 2018$ The Author(s). This is an open-access article distributed under the terms of the Creative Commons Attribution License (http:// creativecommons.org/licenses/by/4.0), which permits unrestricted use, distribution, and reproduction in any medium, provided the original work is properly cited. 
the organism and its relation to the disease. ${ }^{4}$

In 1883, Robert Koch isolated the comma bacillus in a pure culture and explained its mode of transmission - that the vibrio found in the intestines and stools of cholera victims was the causal agent of the disease. ${ }^{5}$ Koch's elucidation of cholera transmission had important public health impacts, such as the strong links between intestinal exposure to contaminated water and cholera in susceptible hosts, with the bacteria returning to water supplies through feces, disseminated through infected individuals engaged in pilgrimages and occupational travels. Koch understood the importance of clean water, and the mass introduction of filtered water pipes which he pioneered led to a fall in the incidence of the disease in Germany in the early 20th century. ${ }^{6}$

Cholera is thought to have started in 1817 in Jessore (now in Bangladesh) and is believed to have spread to Europe by 1823. By 1830 it was reported in Moscow, and the following year the epidemic had reached Warsaw, Berlin, Hamburg, and the northern regions of England. In early 1832, the disease struck London and then Paris. By April 1832, more than 13000 people in Paris had died as a result of cholera. By early June 1832, Canadian cases were reported in Quebec and Montreal. The disease spread along 2 distinct pathways into the United States, with reports from the Mississippi Valley in the summer of 1832 and the first case documented in New York City on June 24, 1832. Cholera's introduction and spread in New York was strongly linked to international trade along the Erie Canal as well as major immigration by poor Irish migrants, some of whom were thought to have contracted the infection in England prior to migrating. ${ }^{\text {? }}$

In the developed world and due to excellent sewage and sanitation systems in place for more than a century, no case of cholera has been reported in the past several decades. However, in the developing world, cholera remains a huge health problem whenever water and sanitation standards are compromised due to poverty, conflicts, or an unstable political climate. It is estimated that, in recent years, there have been 1.3 million to 4 million cases of cholera and 28000 to 243000 deaths attributed to it annually throughout the world. In 2006, 52 countries reported 236896 cholera cases, including 6311 deaths, a case fatality rate of $2.7 \%$. In 2011, a total of 589854 cholera cases, including 7816 cholera deaths, were reported from 58 countries, a case fatality rate of $1.3 \%$. By 2016, 131121 cases and 2420 deaths were reported from 27 countries, representing a case fatality rate of $0.8 \%{ }^{8}$ Underreporting is common; the World Health Organization (WHO) estimates that only $5 \%-10 \%$ of cases occurring annually all over the world are officially reported. Cholera remains a global threat to public health and an indicator of inequity and deficits in social development. ${ }^{9,10}$

This critical review of literature ${ }^{11}$ sought scholarly articles on cholera evolution, transmission, and control from PubMed, CINAHL, Global Health (CABI), Academic Search Complete, and Google Scholar. Search items included Cholera, Quarantine, Global Health, Cholera Pandemics, and International Health Regulations. Items found were reviewed by the 2 authors for relevance, following which 55 eligible articles were utilized in analyzing the complex links between cholera, migration, and global health as well as in developing a conceptual framework for global cholera control.

While it is well established that cholera goes hand-in-glove with poverty and outbreaks are regularly linked with conflict and natural disaster, the impact of migration on cholera transmission is less well-recognized. Also underappreciated in literature are the major contributions of cholera to the development of global health instruments such as the International Health Regulations. This article seeks to address these knowledge gaps and to propose not only technical national and global health approaches to cholera control, but also the need for significant changes in the political, health management, surveillance, and economic landscape of many of the regions affected by cholera.

\section{Cholera Pandemics}

Since the early 1800s, pandemics of cholera have affected many countries, where millions of people have died from acute attacks of the disease. To date, 7 cholera pandemics have been officially recognized, but bacterial strains are currently only available for the sixth and seventh pandemics. The first cholera pandemic, known as "Asiatic cholera", occurred in the Bengal region of India in 1817 and lasted until 1823. By the early 1820 s, colonization, migration, and trade had carried the disease from India to Southeast Asia, China, Japan, the Middle East, and southern Russia. The most affected cities during the first cholera pandemic were Muscat, Tehran, and Baghdad. About 6000 British troops were estimated to have died from the disease in India during this pandemic, as were 10000 Indonesians. $^{12}$

In 1829, the second cholera pandemic started in India and subsequently spread to Russia and then to Poland, Germany, Sweden, Austria, and England in 1831, and further to China and the United States. The pandemic lasted until 1835. The first incidence of cholera in England occurred in Sunderland in October 1831, when a ship carrying sailors and cargo handlers who had the disease docked at the port. The ship was allowed to dock, because port authorities objected to, and therefore ignored, instructions from the government to quarantine all ships coming from Riga (Croatia) port, from which a cholera outbreak had been reported. From Sunderland, the disease spread northwards into Scotland and southwards toward London. Before it had run its course, the disease had claimed at least 52000 lives. ${ }^{13}$ Irish immigrants fleeing poverty and the potato famine carried the disease from Europe to North America. At the beginning of June 1832, the Carrick, a ship that had come over from Ireland, reached Quebec with a few feverish immigrants on board. Three days later, cholera killed its first victim. By the end of 1832, the epidemic had claimed 9000 lives, more than half of them in Lower Canada. Some Canadians held the United Kingdom responsible for this severe outbreak, citing its forced emigration policy for negligence, if not malevolence. ${ }^{14}$ Another cholera outbreak across England and Wales began in 1848, killing 52000 in less than 2 years. The epidemic was concentrated in the Lambeth neighborhood. Efforts to address this epidemic stimulated the passage of the world's first public health law, the 1848 British Health Act. The purpose of this act was to promote 
the public's health and to ensure "more effective provision ... for improving sanitary conditions of towns and populace places in England and Wales." The act identified all the major public health issues of the time and established a structure for dealing with them. ${ }^{15}$

The third pandemic (1852-1863) is generally considered the most deadly. It originated once again in India. In Russia, it caused the deaths of more than one million people and of 23000 people throughout Great Britain. The British physician John Snow undertook detailed epidemiological investigations of this outbreak and was able to demonstrate that cholera was not airborne, but was mainly transmitted through water contaminated with the yet to be identified cholera pathogen. His perseverance and meticulous investigation of the Broad Street cholera epidemic is generally viewed as an important milestone in the evolution of epidemiology as a core specialty of global health. ${ }^{16,17}$ In 1852, cholera spread east to Indonesia and was later carried to China and Japan in 1854. Also in 1854, an outbreak of cholera in Chicago took the lives of $5.5 \%$ of the population (about 3500 people). In 1855, cholera spread from the Arabian Peninsula into Syria and Asia Minor (Turkey). Among the other countries affected were Egypt, Sudan, Morocco, the Cape Verde Islands, Italy, and the adjoining areas of Austria and Switzerland, as well as Venezuela and Brazil. The Philippines was infected in 1858 and Korea a year later. Between 1856 and 1858, Spain and Portugal were the only European countries to be seriously affected. The Philippines in 1858 and Korea in 1859 experienced major outbreaks. In 1859 , an outbreak in India's Bengal region contributed to the transmission of the disease by travelers and troops to Iran, Iraq, Arabia, and Russia. Africa was severely affected, with the disease spreading from its eastern coast into Ethiopia and Uganda. ${ }^{18,19}$

The fourth cholera pandemic (1863-1879) began, again, in the Bay of Bengal, from which Indian Muslim pilgrims visiting Mecca spread the disease to the Middle East. The spread of cholera epidemics that resulted from passenger overcrowding on pilgrim ships had been a major issue in Europe since the 1860 s, when the international community associated the hajj with the outbreak and spread of infectious diseases. At least 30000 of the $90000 \mathrm{Mecca}$ pilgrims were infected with the disease in 1865 , and 15000 died as a result. ${ }^{20}$ Through the movement of pilgrims from Asia to Arabia, the disease spread to the Gulf region and across to Europe. The deaths of at least 180000 people worldwide in 1865 prompted the European powers to call an international sanitary conference in 1866 in Istanbul. ${ }^{21}$ Delegates concluded that the disease originated in India and was spread to the Gulf region by pilgrims before it moved on into Europe. They recommended that quarantine stations should be established at the Tor and Kameran islands on the northern and southern points of the Red Sea, and checks be made on all pilgrims before they alighted in present day Saudi Arabia, to prevent a recurrence of the disease spreading to Europe. Despite improved surveillance, cholera claimed 90000 lives in Russia in 1866. The epidemic of cholera that spread with the Austro-Prussian War (1866) is estimated to have taken 165000 lives in the Austrian Empire, including 30000 each in Hungary and Belgium and 20000 in the Netherlands. ${ }^{22,23}$

The fifth pandemic (1881-1896) originated in the Bengal region of India and swept through Asia, Africa, South America, and parts of France. Between 1883 and 1887, the epidemic cost 250000 lives in Europe and at least 50000 in the Americas. In 1892, cholera claimed 267890 lives in Russia, 120000 in Spain, 90000 in Japan, and over 60000 in Persia. ${ }^{24}$ In Egypt, cholera claimed more than 58000 lives. The 1892 outbreak in Hamburg killed 8600 people. The Hamburg outbreak ultimately led to increased cooperation between the state and scientific institutions to improve public hygiene in cities. Robert Koch, who co-discovered the cholera pathogen, was contracted to consult on the Hamburg epidemic. He decried the state of public hygiene, particularly in the city's slum quarters. The cholera epidemic in Hamburg led to the construction of the city's first waste incinerator, a sewage system, and a filtering plant for drinking water. The slum quarters, where buildings had been tightly packed together, were rebuilt. This was the last serious European cholera outbreak, as cities improved their sanitation and water systems. ${ }^{25}$

The sixth wave of the cholera epidemic occurred between 1899 and 1923. This pandemic killed more than 800000 in India before moving into the Middle East, northern Africa, and Russia. Western Europe was not significantly affected by this epidemic because of remarkable advances in public health following the discovery of cholera transmission patterns and implementation of proven prevention measures. However, major Russian cities and the Ottoman Empire were particularly hard hit by cholera deaths. More than 500000 people died of cholera in Russia from 1900 to 1925, which was also a time of social disruption because of the Russian Revolution. The 1902-1904 cholera epidemic claimed 200000 lives in the Philippines, including the country's first prime minister, Apolinario Mabini. ${ }^{26}$ Cholera broke out 27 times during the hajj at Mecca from the 19th century to $1930 .{ }^{27}$ The last outbreak in the United States was in 1910-1911, when the steamship Moltke brought infected people from Naples to New York City. Vigilant health authorities isolated the infected in quarantine on Swinburne Island. Eleven people died, including a healthcare worker at the hospital on the island. ${ }^{28}$

Unlike the first six that originated in India's Bay of Bengal, the seventh cholera pandemic (1961 to date) originated in Indonesia. It infected thousands of communities in Asia and the Middle East, eventually reaching Africa by 1971. By 1973, the pandemic had spread to Italy. There were also small outbreaks of the same strain - El Tor - in Japan and the South Pacific late in the same decade. ${ }^{29-31}$ In 1991, 100 years after cholera was eradicated from South America, there was an outbreak in Peru that spread across the continent killing 10000 people. $^{32}$ The cholera epidemic in Latin America was originally suspected to have come from Asia and to have been facilitated by the discharge of contaminated ballast water into Peruvian ports by international trade ships. ${ }^{33}$ In addition, a novel serotype caused major outbreaks on the Indian subcontinent - especially in Chennai and Southern Bangladesh - in 1992. That strain was referred to as O139 
Bengal and was later shown to be a variant of the seventh pandemic clone with its replacement of the $\mathrm{O}$ antigen. ${ }^{34}$ In July 1994, one of the worst cholera epidemics broke out among the nearly one million Rwandan refugees in Goma, eastern Zaire. The United Nations High Commission for Refugees estimated that nearly 12000 people died during the epidemic. The overall case fatality rate in treatment centers was nearly $15 \%$ and up to $48 \%$ at several camps due to the rapid waterborne spread of the disease among the refugees, which overwhelmed precarious health services. The high mobility of infected refugees and shigella co-infection contributed significantly to the spread of the epidemic. ${ }^{35}$

\section{Cholera and International Travel}

Cholera has an intricate relationship with international travel. A significant proportion of cholera cases spread through migratory and trade routes, as illustrated in the trajectories of most of the 7 cholera pandemics. Besides water, foods have also been recognized as important vehicles for the transmission of cholera. Foods are likely to be fecally contaminated during preparation, particularly by infected food handlers in an unhygienic environment. Seafood, including fish, shellfish, crabs, oysters and clams, have all been incriminated in cholera outbreaks in many countries, including the United States and Australia. With international travel using ships and airlines, cases of foodborne transmission have increased. ${ }^{36,37}$ Indeed, as transportation systems and trade routes improved and expanded with the industrial revolution, so did the ease and speed of migration, pilgrimage, colonialism, and, concurrently, cholera transmission, which transformed the infection from a localized threat in the Bay of Bengal to a global health challenge. ${ }^{38}$ Migration makes it more likely that uninfected people will visit cholera endemic regions, thereby increasing transmission risk. In Japan, where screening is routine for returning residents with diarrheal-related diseases, the incidence of cholera for all destinations was 5 per 100000 . For Japanese visitors to Bali (Indonesia) who complained of diarrhea, the incidence rate was 13 per $100000 .{ }^{39}$ International travel by United Nations (UN) Nepalese peacekeepers, who presumably were healthy carriers of the cholera microbe, is blamed for the reintroduction of cholera to Haiti after almost a century of cholera-free status. Leaking sewage pipes at the UN base housing infected Nepalese soldiers, who are thought to have transported cholera to Haiti's drinking water supplies ${ }^{40}$ Cholera is endemic to West and Central Africa, where limited access to clean water and sanitation allows for easy transmission. Such epidemics are fueled in part by greater movement of people across the region, especially traders, truck drivers, refuges, and anglers. For example, in weeks 31-40 of 2017 and week 1 of 2018, the Democratic Republic of Congo recorded 18006 and 1027 cases of cholera, respectively, with a $2.4 \%$ case fatality rate. ${ }^{41}$

In its 2010 guidance report on international travel and trade to and from countries experiencing outbreaks of cholera, the WHO stated that:

- Food produced under good manufacturing practices poses only a negligible risk for cholera transmission, and there is currently no evidence that food commercially imported from affected countries has been implicated in outbreaks of cholera in importing countries. The isolated cases of cholera that have been related to imported food have been associated with food which had been in the possession of individual travelers.

- Routine restrictions on movements of people, including quarantine measures or "cordon sanitaire", have been shown to be ineffective in the control of cholera, and are therefore viewed as unnecessary.

- WHO does not consider that requiring proof of vaccination for entry plays a useful role in preventing the international spread of cholera and therefore, such a requirement is considered as an unnecessary interference with international travel. Reference to a requirement for proof of cholera vaccination as a condition for entry was removed from the International Health Regulations in 1973.

- WHO does not advise requiring prophylactic administration of antibiotics or proof of such administration for travelers coming from or going to a country affected by cholera. Routine treatment with antibiotics, or preventive chemoprophylaxis, has no effect on the spread of cholera. Such use of antibiotics can have adverse effects by increasing antimicrobial resistance and provides a false sense of security.

- Countries receiving trade or travelers from a choleraaffected area should improve disease surveillance to obtain better data for risk assessment and early detection of outbreaks, including establishing an active surveillance system. ${ }^{42}$

Although the mainstays of control measures during epidemics remain the appropriate treatment of cholera patients, improvement of water and sanitation, and mobilizing communities, 2 oral doses of cholera vaccines given 2 weeks apart constitute a useful complementary pre-emptive or reactive approach for preventing the spread of cholera outbreaks. There are 2 approved vaccines: (1) Dukoral (WC$\mathrm{rBS}$ ), a monovalent oral vaccine based on formalin and heatkilled whole-cells of $\mathrm{V}$. cholerae O1 plus recombinant cholera toxin B subunit; (2) Shanchol and mORCVAX, bivalent oral vaccines based on serogroups O1 and O139; these vaccines are closely related but formulated by different manufacturers. Dukoral induces efficacious short-term protection; $85 \%$ (95\% CI $56-95 \%$ ) overall, and $100 \%$ (95\% CI 80-100\%) in children aged 2-5 years at 4-6 months of follow up. With a single dose of Shanchol, vaccine protective efficacy was $40 \%$ (95\% confidence interval, $11 \%$ to $60 \%){ }^{43}$

\section{Cholera and Global Health}

Cholera may be regarded as the laboratory for the evolution of global health. From its presumed origins in the Bay of Bengal in the early 1800s, cholera remains one of the major global health challenges of the 21 st century. Cholera-related milestones in global health include: elucidating the role of microbes in the etiology of the disease, thus opening up the field of microbiology ${ }^{44}$; heralding the paradigm shift from miasma to contagion perspectives on disease causation, and identification of contaminated water and food supplies in 
infectious disease transmission, thus opening up the field of global epidemiology ${ }^{45}$; heralding the implementation of quarantine measures, refined versions of which are still in use in controlling infectious diseases such as severe acute respiratory syndrome $e^{46,47}$; stimulating the convening of the world's first international public health conference to address a global health issue, which eventually evolved into the WHO, the world's leading global health body ${ }^{48,49}$; stimulating the development of global health instruments such as the International Health Regulations. ${ }^{50}$

In 2017, the Global Task Force on Cholera Control released a report titled "Ending cholera - a global roadmap to 2030 ". The long-term objective of the roadmap is to ensure reduction of cholera cases by $90 \%$ in the 47 countries currently affected by cholera, and with up to 20 of these countries eliminating cholera as a public health problem. The first of 3 key axes laid out in the roadmap focuses on improving cholera prevention, early detection, and rapid response through enhanced water, sanitation and hygiene (WASH) measures, improved disease surveillance, and laboratory support. The second roadmap axis targets regions where cholera is endemic and outbreaks are recurrent - hotspots - through the integration of accurate morbidity, mortality, and environmental data with an assessment of population vulnerability, existing WASH conditions, and healthcare availability. The final axis lays out the framework for how the roadmap will be implemented, with the need to establish (if not already in existence) nationally led cholera control programs, under international coordination of the WHO Global Task Force on Cholera Control. ${ }^{52}$ The estimated disease burdens in countries affected by cholera in 2015 which were officially reported to the WHO are shown in Table $1 .^{53}$

Cholera remains a major public health risk in the WHO Eastern Mediterranean Region. In fact, most of the dramatic deterioration in cholera cases over the past several years has occurred in this region. For example, compared with the 2015 statistics for cholera in Somalia in Table 1, there were 77774 cases of cholera and 1118 deaths from the disease in Somalia between January and October $2017 .{ }^{54}$ The leading attributing factors are conflicts, poor environmental infrastructure (such as lack of safe drinking water and lack of access to safe sanitation), and increased population movement. It is estimated that the number of cholera cases may be around 188000 per annum. During the past decade, at least 9 out of 22 countries in the region have reported cholera cases, often in epidemic proportions. Explosive outbreaks have been reported from Afghanistan, Djibouti, Iraq, Pakistan, Somalia, Sudan, Syria, and Yemen. ${ }^{55}$ The situation in Yemen is particularly unfortunate; as of 21 December 2017, the International Committee of the Red Cross estimated that the number of cases had reach one million, with at least 2226 deaths since April 2017. The ongoing conflict in Yemen has amplified the spread of cholera, as more than $70 \%$ of Yemenis currently lack food, fuel, water, and access to healthcare. Effective and proven prevention and control measures for cholera are dependent on the provision of an adequate environmental infrastructure, health services, and healthy hygiene measures. In Yemen as in other nations with cholera, the attack rate prevalence varies
Table 1. Cholera Burden in High Prevalence Countries, 2015

\begin{tabular}{|c|c|c|}
\hline & $\begin{array}{c}\text { Range of Cases - } \\
2015\end{array}$ & $\begin{array}{c}\text { Range of Deaths } \\
-2015\end{array}$ \\
\hline Afghanistan & $14670-44011$ & $293-1467$ \\
\hline Angola & $8211-24632$ & $164-821$ \\
\hline Bangladesh & $54526-163578$ & $1091-5453$ \\
\hline Benin & $8274-24821$ & $165-827$ \\
\hline Bhutan & 329-988 & $7-33$ \\
\hline Burundi & $9971-29914$ & 199-997 \\
\hline Cambodia & 496-1487 & $10-50$ \\
\hline Cameroon & $10518-31555$ & 210-1052 \\
\hline Cape Verde & $190-570$ & 4-19 \\
\hline Central African Republic & $5742-17226$ & $115-574$ \\
\hline Chad & $10197-30591$ & 204-1020 \\
\hline China & $4542-13626$ & $91-454$ \\
\hline Comoros & 437-1312 & $9-44$ \\
\hline Congo & $6743-20230$ & $135-674$ \\
\hline Côte d'Ivoire & $28844-86533$ & $577-2884$ \\
\hline Democratic Republic of the Congo & $94531-283592$ & $1891-9453$ \\
\hline Djibouti & 342-1026 & $7-34$ \\
\hline Dominican Republic & 1703-5109 & $96-482$ \\
\hline Eritrea & $10030-32725$ & 218-1091 \\
\hline Ethiopia & $137611-412832$ & $2752-13761$ \\
\hline Gabon & $1043-3128$ & 21-104 \\
\hline Gambia & 538-1613 & $11-54$ \\
\hline Ghana & $20866-62598$ & $417-2087$ \\
\hline Guinea & 8918-26755 & 178-892 \\
\hline Guinea-Bissau & 1269-3808 & $25-127$ \\
\hline Haiti & $16428-49284$ & 2106-10529 \\
\hline India & $337594-1012782$ & $6752-33759$ \\
\hline Indonesia & 1149-3448 & 23-115 \\
\hline Jamaica & $27-82$ & $0-3$ \\
\hline Kenya & $55637-166910$ & $1113-5564$ \\
\hline Lao People's Democratic Republic & $166-499$ & $3-17$ \\
\hline Liberia & $3246-9737$ & $65-325$ \\
\hline Madagascar & $17918-53753$ & 358-1792 \\
\hline Malawi & $14713-44140$ & 294-1471 \\
\hline Mali & $10909-32727$ & 218-1091 \\
\hline Mauritania & 2671-8013 & $53-267$ \\
\hline Mozambique & 39306-117919 & $786-3931$ \\
\hline Namibia & 2963-8890 & 59-296 \\
\hline Nepal & $15189-45568$ & $304-1519$ \\
\hline Niger & 1446343390 & 289-1446 \\
\hline Nigeria & 110198-330595 & 2204-11020 \\
\hline Papua New Guinea & $189-566$ & 4-19 \\
\hline Philippines & $1215-3644$ & 24-121 \\
\hline Rwanda & $9753-29259$ & $195-975$ \\
\hline Sao Tome and Principe & $132-396$ & $3-13$ \\
\hline Senegal & $6216-18649$ & $124-622$ \\
\hline Sierra Leone & $5004-15013$ & $100-500$ \\
\hline Somalia & $6084-18253$ & $122-608$ \\
\hline South Sudan & $14713-44138$ & 294-1471 \\
\hline Sudan & $21634-64901$ & $433-2163$ \\
\hline Swaziland & 1026-3078 & 21-103 \\
\hline Timor-Leste & 469-1407 & $9-47$ \\
\hline Togo & 548616459 & $110-549$ \\
\hline Uganda & $44863-134589$ & $897-4486$ \\
\hline United Republic of Tanzania & $80952-242856$ & 1619-8095 \\
\hline Yemen & $10148-500319$ & $175-2226$ \\
\hline Zambia & $13746-41237$ & $275-1375$ \\
\hline Zimbabwe & 15692-47077 & 314-1569 \\
\hline Total & $1435874-4007622$ & $28558-242786$ \\
\hline
\end{tabular}




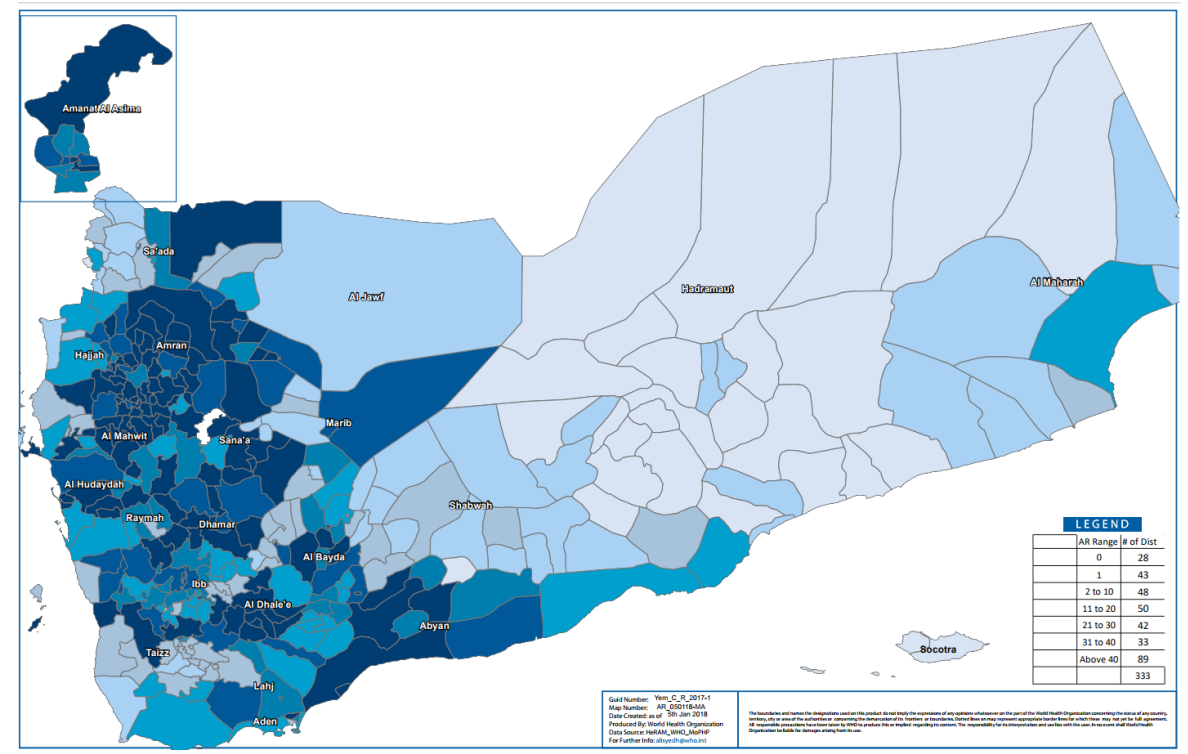

Figure 1. WHO's 2018 Map of Attack Rates in Different Regions of Yemen. Data source: HeRAM_WHO_MoPHP.

from region to region depending on the extent to which social determinants of health in particular, and health services in general, are optimal (Figure 1$)^{56}$ :

The authors propose a framework comprising major influences of the cholera situation in Yemen (Figure 2).

The important determinants of effective cholera prevention and control and the effective provision of health services have been compromised by the ongoing war in Yemen. ${ }^{57}$

\section{Conclusion}

Trends in cholera epidemics constitute a sensitive indicator of the optimality of social determinants of health and of health systems function. Conflicts and refugee situations severely disrupt social determinants of health, and refugees commonly have inadequate access to quality health services ${ }^{58}$ In refugee camps, poverty, overcrowding, unclean water, and inadequate sanitation further increase cholera risk. Health and hygiene concerns may be subjugated to more immediate concerns for security, food, and shelter. ${ }^{59}$ Increasing migration is a fact of our rapidly globalizing planet. Global health has been importantly influenced by human mobility patterns since time immemorial. The challenge is not necessarily to reduce migration (given that, for example, apparently healthy carriers from Nepal re-introduced cholera to Haiti), but to ensure that the movement of people and goods does not constitute a major risk for the transmission of cholera and other infectious diseases.

At the health services level, the 2030 cholera elimination roadmap reiterates that the first step in controlling cholera and dramatically reducing the number of cholera deaths is to support countries in strengthening their capacities for preparedness, early detection, laboratory confirmation, and immediate and effective response to outbreaks in order to reduce the impact of the disease. Also important is the need to break the silos at national and global levels to implement integrated, multi-sectoral actions in cholera hotspots. Furthermore, an effective mechanism of coordination for

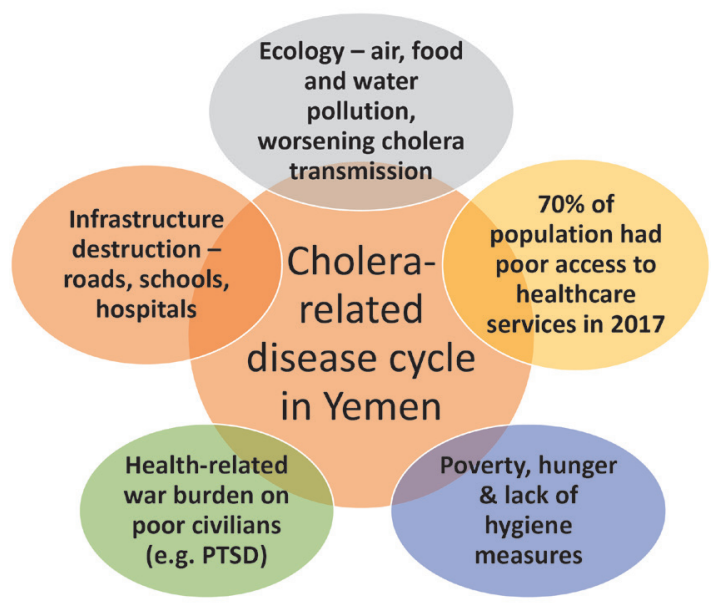

Figure 2. Cholera Migration \& Global Health.

technical support, resource mobilization, and partnership at local and global levels is essential for successful cholera control. Cholera-affected nations need to enhance communication on cholera control strategies, hygiene promotion, and cholera risk by mobilizing community leaders as agents of change. Effective healthcare leadership, intersectoral collaboration, enhanced readiness for cholera outbreaks through capacity building for staff, and pre-positioning of resources for diagnostics, patient care, and emergency water, sanitation, and hygiene interventions are recommended actions.

\section{Authors' Contributions}

All authors significantly contributed towards this study.

\section{Conflict of Interest Disclosures}

None.

Ethical Approval

Not applicable. 


\section{Review Highlights}

\section{What Is Already Known?}

The primacy of cholera as a global public health challenge is well established. The seven recorded pandemics of cholera have caused serious morbidity and mortality in most regions of the world, but the last four pandemics have been particularly concentrated in developing nations or nations with acutely fractured health systems due to natural or conflict-related factors, such as Haiti and Yemen, respectively.

\section{What This Study Adds?}

This critical review article seeks to contribute to the literature on cholera by examining the iterative influences of forced migration on cholera over the past 2 decades. This article highlights how cholera may lead to mass migrations of refugee populations, and how mass migrations, particularly of vulnerable or carrier populations, may increase cholera risk. Further highlighted is how cholera has, more than any other infectious disease, stimulated the evolution of global health, and how global health instruments and intersectoral actions are becoming increasingly indispensable in eliminating cholera as a public health threat in the first half of the 21 st century. The Roadmap to 2030 from the recently revitalized WHO Global Task Force on Cholera Control seeks to reduce cholera deaths by $90 \%$. This article contributes to the literature on the independent variable of mass forced migration on global efforts to address cholera.

\section{Funding/Support}

None.

\section{References}

1. Nair GB, Qadri F, Holmgren J, et al. Cholera due to altered El Tor strains of Vibrio cholerae O1 in Bangladesh. J Clin Microbiol. 2006;44(11):4211-4213. doi:10.1128/jcm.01304-06.

2. Afkhami AA. Defending the Guarded Domain: Epidemics and the Emergence of an International Sanitary Policy in Iran. Comparative Studies of South Asia, Africa and the Middle East. 1999;19(1):122136. doi:10.1215/1089201X-19-1-122.

3. Moshar KA. Bibliography of Persian Printed Books (1808-1967). Tehran: Bongah-e Tarjomeh va Nasher-e Ketab; 1973:3349-50. [Persian].

4. Kousoulis AA. Etymology of cholera. Emerg Infect Dis. 2012;18(3):540. doi:10.3201/eid1803.111636.

5. Frerichs R. Who first discovered cholera? http://www.ph.ucla.edu/ epi/snow/firstdiscoveredcholera.html. Published 2016. Accessed December 12, 2017

6. Howard-Jones N. Robert Koch and the cholera vibrio: a centenary. Br Med J (Clin Res Ed). 1984;288(6414):379-381.

7. Wood GB. A Treatise on the Practice of Medicine. 6th ed. Philadelphia: Lippincott; 1855:23-45.

8. World Health Organization. Cholera - Global Health Observatory data. http://www.who.int/gho/epidemic_diseases/cholera/cases/en/. Accessed 30 January 2018

9. Health Organization. Cholera. http://www.who.int/mediacentre/ factsheets/fs107/en/. Accessed 18 December 2017. Published 2017.

10. World Health Organization. Cholera 2015. Weekly Epidemiological Record. 2016;91(38): 433-440.

11. Grant MJ, Booth A. A typology of reviews: an analysis of 14 review types and associated methodologies. Health Info Libr J. 2009;26(2):91-108. doi:10.1111/j.1471-1842.2009.00848.x.

12. Barua D. Cholera. Pro Roy Soc Med. 1972;65:11-16.

13. United Kingdom Parliament. Cholera in Sutherland. http:// www.parliament.uk/about/living-heritage/transformingsociety/ towncountry/towns/tyne-and-wear-case-study/introduction/cholerain-sunderland/. Accessed 29 January 2018

14. Le Canada. The Cholera Epidemic of 1832. http://www.cbc.ca/ history/EPCONTENTSE1EP7CH1PA5LE.html. Accessed 26 January 2018.

15. Calman K. The 1848 Public Health Act and its relevance to improving public health in England now. BMJ. 1998;317(7158):596-598. doi:10.1136/bmj.317.7158.596.

16. Snow J. On the Mode of Communication of Cholera. London: John Churchill; 1855.

17. Fine $\mathrm{P}$, Victora CG, Rothman KJ, et al. John Snow's legacy: epidemiology without borders. Lancet. 2013;381(9874):13021311. doi:10.1016/s0140-6736(13)60771-0.

18. UCLA School of Public Health. Asiatic Cholera Pandemic of 184663. http://www.ph.ucla.edu/epi/Snow/pandemic1846-63.html. Accessed 30 January 2018

19. Azizi M, Azizi F. History of Cholera Outbreaks in Iran during the 19(th) and 20(th) Centuries. Middle East J Dig Dis. 2010;2(1):51-55.

20. Maslan A. Hajj and the Malayan Experience, 1860s-1941. Kemanusiaan. 2014;21(2):79-98.

21. Bashford A. The Age of Universal Contagion: History, Disease and Globalization. In: Bashford A, ed. Medicine at the Border. London: Palgrave Macmillan; 2007:1-7. doi:10.1057/9780230288904_1.

22. The Myadel Region. Eastern European plagues and epidemics. https://kehilalinks.jewishgen.org/Myadel/pandemics.htm. Accessed 27 January 2018.

23. Byrne P. Encyclopedia of pestilence, pandemics, and plagues. http:// www.academia.dk/MedHist/Sygdomme/PDF/Encyclopedia_of_ Pestilence_Pandemics_and_Plagues.pdf. Accessed 26 January 2018.

24. Kaper JB, Morris JG Jr, Levine MM. Cholera. Clin Microbiol Rev. 1995;8(1):48-86.

25. GHDI. Cholera Epidemic in Hamburg (1892). http://ghdi.ghi-dc.org/ sub_image.cfm?image_id=1608. Accessed 27 January 2018.

26. Philippine History in Pictures. May 13, 1903: Apolinario Mabini Died of Cholera. https://philhistorypicts.blogspot.ae/2015/05/may13-1903-apolinario-mabini-died-of.html. Accessed 25 January 2018.

27. Claeson M, Waldman R. Cholera. Encyclopedia Britannica. https:// www.britannica.com/science/cholera. Accessed 29 January 2018.

28. Sen S. Indian Cholera: A Myth. Indian J Hist Sci. 2012;47:345-374.

29. Bwire G, Malimbo M, Maskery B, Kim YE, Mogasale V, Levin A. The burden of cholera in Uganda. PLoS NegITrop Dis. 2013;7(12):e2545. doi:10.1371/journal.pntd.0002545.

30. Reeves PR, Lan R. Cholera in the 1990s. Br Med Bull. 1998;54(3):611623.doi:10.1093/oxfordjournals.bmb.a011714.

31. Horwood PF, Collins D, Jonduo MH, et al. Clonal origins of Vibrio cholerae O1 El Tor strains, Papua New Guinea, 2009-2011. Emerg Infect Dis. 2011;17(11):2063-2065. doi:10.3201/eid1711.110782.

32. Tauxe RV, Blake PA. Epidemic cholera in Latin America. JAMA. 1992;267(10):1388-1390. doi:10.1001/jama.1992.03480100098039.

33. Seas C, Miranda J, Gil Al, et al. New insights on the emergence of cholera in Latin America during 1991: the Peruvian experience. Am J Trop Med Hyg. 2000;62(4):513-517. doi:10.4269/ ajtmh.2000.62.513.

34. Singh DV, Matte MH, Matte GR, et al. Molecular analysis of Vibrio cholerae O1, O139, non-O1, and non-O139 strains: clonal relationships between clinical and environmental isolates. Appl Environ Microbiol. 2001;67(2):910-921. doi:10.1128/ aem.67.2.910-921.2001.

35. Siddique AK. Cholera epidemic among Rwandan refugees: experience of ICDDR,B in Goma, Zaire. Glimpse. 1994;16(5):3-4.

36. Eberhart-Phillips J, Besser RE, Tormey MP, et al. An outbreak of cholera from food served on an international aircraft. Epidemiol Infect. 1996;116(1):9-13. doi:10.1017/S0950268800058891.

37. Sutton RG. An outbreak of cholera in Australia due to food served in 
flight on an international aircraft. J Hyg (Lond). 1974;72(3):441-451. doi:10.1017/S0022172400023688.

38. Boyle SA. Cholera, Colonialism, and Pilgrimage: Exploring Global/ Local Exchange in the Central Egyptian Delta, 1848-1907. J World Hist. 2015;26(3):581-604. doi:10.1353/jwh.2015.0039.

39. Sanchez JL, Taylor DN. Cholera. Lancet. 1977;349(9068):18251830. doi:10.1016/S0140-6736(97)04486-3.

40. Frerichs RR, Keim PS, Barrais R, Piarroux R. Nepalese origin of cholera epidemic in Haiti. Clin Microbiol Infect. 2012;18(6):E158163. doi:10.1111/j.1469-0691.2012.03841.x.

41. UNICEF. Cholera Outbreaks in Central and West Africa: 2018 Regional Update. https://www.plateformecholera.info/images/ WCA_Cholera_Update_W2-2018.pdf. Accessed 3 April 2018.

42. World Health Organization. WHO statement relating to international travel and trade to and from countries experiencing outbreaks of cholera. Geneva: WHO, 2010. http://www.who.int/cholera/ technical/prevention/choleratravelandtradeadvice231110.pdf.

43. Qadri F, Wierzba TF, Ali M, et al. Efficacy of a Single-Dose, Inactivated Oral Cholera Vaccine in Bangladesh. N Engl J Med. 2016;374(18):1723-1732. doi:10.1056/NEJMoa1510330.

44. Koch R. An Address on Cholera and its Bacillus. Br Med J. 1884;2(1235):403-407. doi:10.1136/bmj.2.1235.403.

45. Cameron D, Jones IG. John Snow, the broad street pump and modern epidemiology. Int J Epidemiol. 1983;12(4):393-396. doi:10.1093/ ije/12.4.393.

46. Moore WJ. Cholera and quarantine. Lancet. 1883;122(3124):77-78. doi:10.1016/S0140-6736(02)36191-9.

47. Hsieh $\mathrm{YH}$, King CC, Chen CW, et al. Quarantine for SARS, Taiwan. Emerg Infect Dis. 2005;11(2):278-282. doi:10.3201/ eid1102.040190.

48. Howard-Jones $\mathrm{N}$. The scientific background of the international Sanitary Conferences, 1851-1938. Geneva: WHO; 1975. http:// apps.who.int/iris/bitstream/10665/62873/1/14549_eng.pdf.
Accessed 30 January 2018.

49. World Health organization. The first 10 years of the World Health Organization. http://apps.who.int/iris/bitstream/10665/37089/14/ a38153_eng_LR_part1.pdf. Accessed 30 January 2018.

50. Mack E. The World Health Organization's New International Health Regulations: Incursion on State Sovereignty and III-Fated Response to Global Health Issues. Chic J Int Law. 2006;7(1):365-377.

51. Global Task Force on Cholera Control. Ending cholera - a global roadmap to 2030. http://www.who.int/cholera/publications/globalroadmap.pdf. Accessed 20 January 2018.

52. Reduction in cholera deaths targeted for 2030. Nature Microbiol. 2017;2(11):1457. doi:10.1038/s41564-017-0055-9.

53. Ali M, Nelson AR, Lopez AL, Sack DA. Updated global burden of cholera in endemic countries. PLoS Negl Trop Dis. 2015;9(6):e0003832. doi:10.1371/journal.pntd.0003832

54. UNICEF. Bulletin: Cholera - AWD Outbreaks in Eastern and Southern Africa. Regional Update - as at 5 October 2017. https://reliefweb.int/ sites/reliefweb.int/files/resources/Cholera\%20Bulletin_Eastern\%20 and\%20Southern\%20Africa\%20Region_\%20as\%20at\%205\%20 October\%202017.pdf. Accessed 3 April 2014.

55. WHO EMRO. Cholera outbreak, 2018. http://www.emro.who.int/ health-topics/cholera-outbreak/index.html. Accessed 30 January 2018.

56. World Health organization. Cholera attack rate from 27 April 2017 to 5 January 2018. https://reliefweb.int/sites/reliefweb.int/files/ resources/050118_attackrate_who_color.pdf.

57. Balakrishnan VS. Cholera in Yemen. Lancet Infect Dis.2017;17(7):700701.doi:10.1016/S1473-3099(17)30352-3.

58. Schaetti C, Sundaram N, Merten S, et al. Comparing sociocultural features of cholera in three endemic African settings. BMC Med. 2013;11:206. doi:10.1186/1741-7015-11-206.

59. Phares CR, Ortega L. Crossing borders: one world, global health. Clin Infect Dis. 2014;58(1):iv-v. doi:10.1093/cid/cit762. 